\title{
Value of theophylline treatment in patients handicapped by chronic obstructive lung disease
}

\author{
Sheila E McKay, Catherine A Howie, Alison H Thomson, Brian Whiting, George J Addis
}

\begin{abstract}
Background It is still not certain whether it is worth using theophylline in addition to inhaled bronchodilators and corticosteroids to treat obstructive airways disease. This trial was designed to test whether the addition of prescribed theophylline in doses sufficient for sustained optimal steady state plasma concentrations would produce any detectable additional advantage in spirometric or functional variables in these handicapped patients.
\end{abstract}

Methods A randomised, double blind, placebo controlled, crossover study of added theophylline treatment was aimed at steady state plasma concentrations of 10 and $17 \mathrm{mg} / 1$, the dose being calculated individually by Bayesian parameter estimation and maintained for six weeks along with the patient's previously prescribed bronchodilators and steroids. Of 20 patients sequentially recruited, 15 provided data that could be analysed. All had chronic obstructive lung disease with a mean forced expiratory volume in the first second $\left(F E V_{1}\right)$ up to about $30 \%$ of the predicted value and gave no history of being treated with theophylline. The protocol included spirometry, whole body plethysmography, and treadmill exercise. Measurements also included steady state plasma theophylline concentrations and trapped gas volume. Quality of life was assessed by an established questionnaire method covering breathlessness in everyday activities, fatigue, emotional function, and control over the disease.

Results Both target plasma concentrations were achieved. Improvements in peak flow (PEF; mean 20\%), trapped gas volumes $(38 \%)$, two stage vital capacity $(15 \%)$, distances walked $(48 \%)$, breathlessness in everyday activities (32\%), and fatigue $(18 \%)$ were found at the higher plasma concentration only. $F E V_{1}$, forced vital capacity (FVC), emotional function, and control did not change.

Conclusion Theophylline treatment with sustained steady state concentrations about $17 \mathrm{mg} / \mathrm{l}$ provides worthwhile objective and subjective further benefits for patients handicapped by chronic obstructive lung disease when it is added to bronchodilators and corticosteroids.

(Thorax 1993;48:227-232)
Despite the extensive publications there is still argument over the value of theophylline in severe chronic obstructive lung disease. ${ }^{1-3}$

Results of simple lung function tests are known to bear no consistent relation to functional impairment. ${ }^{4}$ They are also poor predictors of exercise capacity. ${ }^{5-7}$ Exercise is usually limited by subjective sensations that are not easily measured. Various semi-objective assessment scales have been used with varying results. ${ }^{89}$

Perhaps more important but even more difficult to measure is the effect of treatment on the quality of life. Only one group of workers has used a method to quantify patients' feelings about their illness as well as the extent of their physical disability. ${ }^{10}$

A further problem is that the relation between the plasma concentration and the effect of theophylline is not direct. ${ }^{11}$ The peak effect of a single dose may lag about four hours behind the peak of the plasma concentration. Some effect is present after the plasma concentration has fallen below the limit of detection. ${ }^{12}$ Single dose studies or studies where a steady plasma concentration has not been achieved and maintained consistently throughout are therefore very likely to contain confounding errors.

In addition, it seems possible that effects on the inflammatory response ${ }^{1314}$ and their consequences are not detected by single dose or short term studies.

We report here a longer term study of the effects of theophylline, at two dosages of a slow release preparation, in patients with severe disease, based on simple spirometry, plethysmography, exercise testing, and quality of life measures. The study was double blind, placebo controlled, and crossed over, with steady state plasma concentrations maintained for at least six weeks for each phase.

\section{Methods}

SELECTION OF PATIENTS

We recruited in sequence all the new patients referred to our routine hospital chest clinic with stable chronic obstructive lung disease as defined by the American Thoracic Society. ${ }^{15}$ We excluded all who could recall any previous theophylline treatment and those with any personal or family history suggesting asthma or atopy or evidence of any concurrent disease. Every effort was made to ensure that all suitable patients were admitted to the trial. The study was approved by the hospi-

\author{
Received 5 December 199 \\ Returned to Authors \\ 24 January 1992 \\ Revised version received \\ Accepted 8 September 1992


tal's research and ethical committee and all patients gave their informed written consent.

\section{STUDY DESIGN}

Patients attended for baseline measurements and were then randomly allocated to the order of treatment with placebo and low with high dose theophylline by a multiple $(3 \times 3)$ Latin square design. The three study periods were otherwise identical. Drug dosage was established in the first two weeks of each period as described below and maintained for five further weeks. At the end of the seventh week measurements of lung function, exercise capacity, and quality of life indices were done. All measurements were made at the same time of day for each patient. Resting pulse and blood pressure were also measured. Oxygen saturation, subjective breathlessness, and heart rate during exercise were also monitored as precautionary measures.

\section{DETAILS OF DRUG DOSAGE}

Each patient was prescribed identical tablets containing either $200 \mathrm{mg}$ of theophylline or placebo, depending on the phase of the study. The starting dose in the first week of each study was $200 \mathrm{mg}$ twice daily. The plasma concentration was measured at the end of this week and the dose necessary to achieve a steady state concentration of $10 \mathrm{mg} / \mathrm{l}$ (low dose) or $17 \mathrm{mg} / \mathrm{l}$ (high dose) was then determined for each individual by Bayesian parameter estimation (the OPT programme). ${ }^{16}$ The plasma concentration was determined again at the end of the second week to confirm that the desired concentration was being achieved. The individual dosage based on these estimations was maintained for the remaining five weeks of that period of the study. A further plasma concentration was then obtained. Each of these samples was used to calculate theophylline clearances and the steady state concentration achieved. The placebo tablets were adjusted randomly at the same stage of the placebo period to maintain the blind.

Compliance was assessed by counting tablets. Six to fifteen extra tablets were supplied in each bottle and the number returned was counted at the next visit. Poor compliance was suspected if tablet counts diverged by more than five from the expected number. Only the pharmacist knew the treatment order and dosage regimen for each patient. Throughout the study all patients continued to take steady doses of their inhaled $\beta$ agonists and ipratropium as prescribed. Those already having inhaled or oral steroids continued to take a constant dose. The same procedure was followed during each of the three stages of the study.

\section{LUNG FUNCTION AND EXERCISE TESTS}

PEF, $\mathrm{FEV}_{1}$, and forced vital capacity (FVC) were determined as previously described. ${ }^{17}$ The two stage vital capacity (VC) was determined as the sum of satisfactory tracings of the inspiratory capacity and of the expiratory reserve volume. Trapped gas volume (defined by Comroe's group ${ }^{18}$ ) was the numerical difference between measurements of functional residual capacity made by the separate techniques of whole body plethysmography and closed circuit helium dilution. As the difference should be the same at all levels within a vital capacity we followed Chrystyn and colleagues $^{19}$ and measured at total lung capacity (TLC), using an automated method ${ }^{20}$ for constant volume plethysmography and a standard closed circuit apparatus (P K Morgan, model PTB).

Exercise performance was assessed by a symptom limited treadmill test based on that developed by Stark and Guz. ${ }^{21}$ Each patient chose the speed and slope of the treadmill that induced moderate dyspnoea after about five minutes' walking. The treadmill was run continuously at these same settings on each subsequent study day and was stopped when the patient decided to walk no further. This end point was not otherwise specified.

\section{CHRONIC RESPIRATORY DISEASE} QUESTIONNAIRE

We adopted the questionnaire developed by Guyatt et $a l^{10}$ specifically to assess patients with severe respiratory disability. In it the patient chooses the five most important activities of regular daily life that invariably induce breathlessness. Each activity is scored separately on a seven point scale, where "no breathlessness" scores 7. Further questions are related to other aspects of life affected by respiratory disease namely, fatigue, emotional condition, and the feeling of control over the disease (mastery). These are scored in the same way. The results provide data in terms of rational numbers suitable for statistical analysis. For simplicity we have reported the scores on $0-100$ scales.

\section{STATISTICAL ANALYSIS}

Clearance estimates following low and high doses were compared by means of paired Student's $t$ tests. All response variables were analysed by two way analysis of variance to test for treatment effects at a level of 0.05. Follow up Bonferroni multiple comparisons provided overall $95 \%$ confidence intervals (CI) to identify specific within patient treatment differences. The resulting confidence intervals for the differences between the means for the active and the placebo treatment are presented in the results. The study was designed to detect real differences of the order of $20 \%$ on the basis of the variances in comparable subjects reported in published studies with the conventional criterion for significance of $<5 \%$ and $70 \%$ power. The loss of some patients (see below) and the variability in some measurements during the study reduced this expectation. The appropriate resulting minimum detectable differences are given in the results.

\section{Results}

Twenty patients were recruited, of whom 15 provided complete data for the placebo and 
Table 1 Details of the patients initially recruited to the trial

\begin{tabular}{cclll}
\hline $\begin{array}{l}\text { Patient } \\
\text { No }\end{array}$ & Age & Sex & $\begin{array}{l}\text { FEV } \\
\text { (\%pred) }\end{array}$ & $\begin{array}{l}\text { Reversibilityt } \\
(\%)\end{array}$ \\
\hline 1 & 76 & M & $0.50(17)$ & 4 \\
2 & 45 & F & $0.45(18)$ & 8 \\
3 & 61 & M & $1.10(52)$ & 10 \\
$\star 4$ & 66 & M & $1.49(56)$ & 20 \\
5 & 48 & M & $0.48(12)$ & 13 \\
$\star 6$ & 41 & F & $0.87(31)$ & 6 \\
$\star 7$ & 62 & M & $0.44(17)$ & 0 \\
$\star 8$ & 54 & F & $0.28(12)$ & 0 \\
9 & 52 & M & $1.59(29)$ & 37 \\
10 & 57 & M & $1.20(42)$ & 33 \\
11 & 51 & M & $0.85(21)$ & 18 \\
12 & 69 & F & $0.64(30)$ & 14 \\
$\star 13$ & 66 & F & $0.53(28)$ & 20 \\
14 & 59 & M & $1.63(59)$ & 4 \\
15 & 37 & M & $1.52(47)$ & 21 \\
16 & 64 & M & $0.43(12)$ & 19 \\
17 & 49 & F & $0.46(44)$ & 10 \\
18 & 49 & F & $0.50(22)$ & 6 \\
19 & 63 & M & $1.17(27)$ & 21 \\
20 & 68 & F & $0.67(33)$ & 20 \\
Mean & 57 & & $0.84(31)$ & 14 \\
SD & 10 & & $0.44(15)$ & 10 \\
\hline
\end{tabular}

*These five subjects did not provide data sufficient for inclusion in the analysis (see under "Results").

†Reversibility is the percentage increase from baseline FEV, measured 20 minutes after inhalation of $200 \mu \mathrm{g}$ salbutamol from a spacer type inhaler.

high dose phases. One claimed never to have smoked, one was an ex-smoker of over 10 years' standing, and the rest were current smokers or had recently quitted smoking. All the smokers had had 20 cigarettes or more daily for at least 20 years.

Table 1 gives the demographic details and baseline lung function, including percentage reversibility in response to $200 \mu \mathrm{g}$ of salbutamol administered with a spacer device. One subject deteriorated rapidly during the last weeks of the study in his low dose phase and died in another hospital from respiratory failure. Thus 14 patients were included in the low dose phase. Patient 8 died of bronchopneumonia during the first phase of the study while on the high dose regimen. Patient 6 defaulted in the first (placebo) phase without explanation. Three (Nos 4, 7, 13) refused to continue on the grounds of nausea that they

Table 2 Spirometric data on placebo and at mean (SD) steady state theophylline concentrations ( $C p_{s s}$ of $10 \cdot 0(2 \cdot 0)$ and $18 \cdot 2(4 \cdot 6) \mathrm{mg} / \mathrm{l})$

\begin{tabular}{|c|c|c|c|}
\hline & & $C p_{s s}$ & $C p_{s s}$ \\
\hline & Placebo & Lower & Higher \\
\hline \multicolumn{4}{|c|}{$\operatorname{PEF}(1 / \mathrm{min})$} \\
\hline Mean & 146 & 160 & $176^{\star}$ \\
\hline SD & 66 & 72 & 67 \\
\hline \multicolumn{4}{|l|}{$\mathrm{FEV}_{1}(\mathrm{l})$} \\
\hline Mean & 0.92 & $1 \cdot 02$ & 1.05 \\
\hline SD & 0.45 & 0.5 & 0.46 \\
\hline \multicolumn{4}{|l|}{ FVC (1) } \\
\hline Mean & 1.93 & $2 \cdot 14$ & $2 \cdot 2$ \\
\hline SD & $0 \cdot 87$ & 0.9 & 0.83 \\
\hline \multicolumn{4}{|c|}{ 2-st VC (I) } \\
\hline Mean & $2 \cdot 33$ & $2 \cdot 64^{\star}$ & $2 \cdot 67^{\star}$ \\
\hline $\mathrm{SD}$ & 0.9 & 0.97 & $0 \cdot 89$ \\
\hline
\end{tabular}

* Significantly different from corresponding placebo value (see under "Results" for details).

PEF-peak expiratory flow; $\mathrm{FEV}_{1}$-forced expiratory volume in one second; FVC-forced vital capacity; 2 -st VC- - two stage vital capacity. ascribed to the treatment. None had a plasma theophylline level above $5 \mathrm{mg} / \mathrm{l}$ at the time. No usable data were obtained from these five patients. Patient 18 could not perform the treadmill test for the high dose period because of an ankle injury. Otherwise her data were complete. Patient 14 was admitted to hospital on two occasions during the study. His trial treatment was maintained but no data were collected for two weeks after these minor exacerbations. Of those who completed the study, none had any adverse complaints while on the low dose. Three patients reported occasional nausea on the high dose but chose to continue.

\section{PHARMACOKINETICS}

The modal daily dose in the low dose period was $600 \mathrm{mg}$ and that in the high dose period $1200 \mathrm{mg}$. The mean (SD) values of the calculated individual average steady state concentrations were $10.0(2.0) \mathrm{mg} / 1$ in the low dose and $18.2(4.6) \mathrm{mg} / 1$ in the high dose period. The mean measured concentration with the low dose was $9 \cdot 1(2 \cdot 3) \mathrm{mg} / 1$. With the high dose it was $16 \cdot 8(4 \cdot 2) \mathrm{mg} / 1$. Clearance estimates ranged from 0.9 to $5 \cdot 21 / \mathrm{h}$. Intrasubject variability in clearance (based on four to six estimates per patient) ranged from $15 \%$ to $34 \%$ (mean $22 \%$ ). Mean (SD) clearance estimates with the low dose and the high dose were not significantly different at $2 \cdot 4(0 \cdot 8)$ and $2 \cdot 1(0 \cdot 8) 1 / \mathrm{h}$. Tablet counts confirmed acceptable compliance.

\section{LUNG FUNCTION DATA}

Table 2 summarises the simple spirometric indices at baseline and with the three treatment regimens. Peak flow increased with theophylline treatment $(p<0.05)$ but was significantly higher only at the higher dose (CI 2 to $581 / \mathrm{min}$ ). The two stage VC was

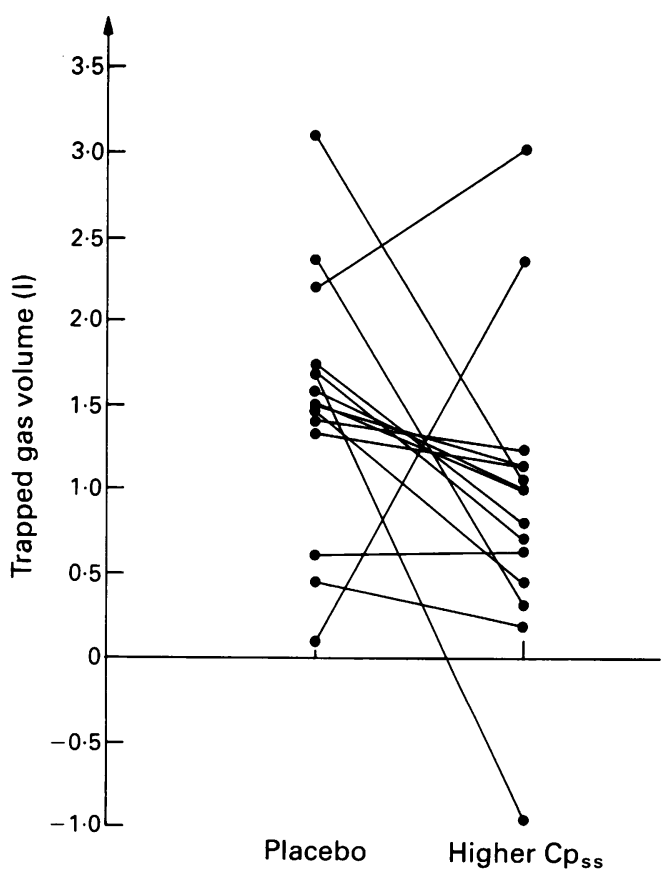

Figure 1 Trapped gas volumes with placebo and at the higher average steady state plasma concentration $\left(C p_{s s}\right)$ of theophylline. 
Figure 2 Distances walked with placebo and at the higher average steady state plasma concentration $\left(C p_{s s}\right)$ of theophylline.

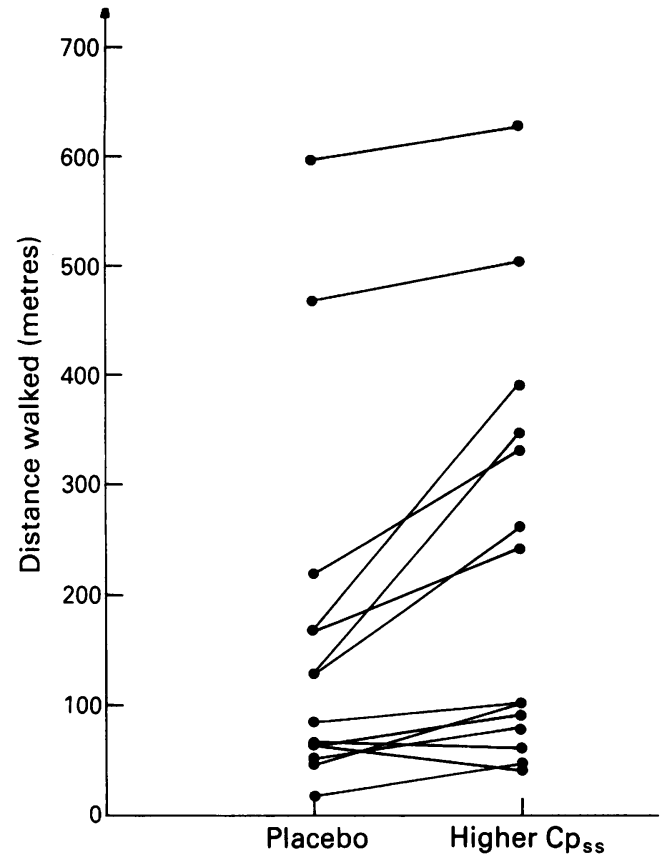

significantly $(p<0.001)$ higher than placebo at both low (CI 0.1 to 0.451 ) and high (CI 0.14 to 0.521 ) dosage. There was no significant difference in $\mathrm{FEV}_{1}$ or FVC. The minimum detectable mean differences defined above for $\mathrm{FEV}_{1}$ was $320 \mathrm{ml}(38 \%)$ and for FVC $540 \mathrm{ml}(31 \%)$. Figure 1 shows the individual changes in trapped gas volume with placebo and at the higher of the two steady state concentrations as it is significantly less $(\mathrm{p}<0.05)$ at this level only (CI -1.17 to $-0.021)$.

\section{EXERCISE DATA}

The distance walked at a constant work rate is shown in fig 2 . The differences between the high dose and its placebo are significant ( $p<$ 0.05 ) with the $95 \%$ confidence intervals of the differences being 7 to $126 \mathrm{~m}$. The low dose comparisons are not significantly differ-

Figure 3 Self rated breathlessness scores in everyday activities $(100=$ "no symptoms") with placebo and at the higher average steady state plasma concentration $\left(C p_{s s}\right)$ of theophylline.

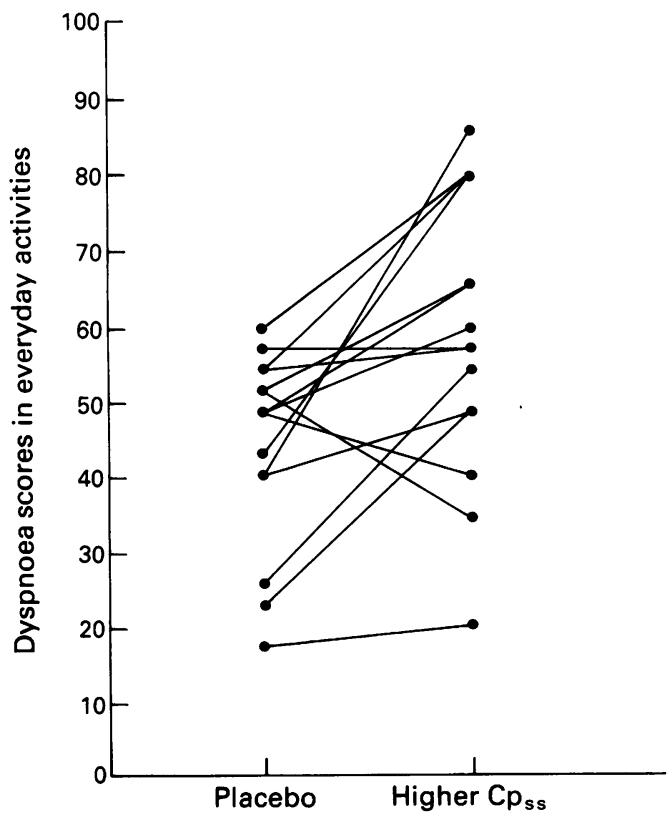

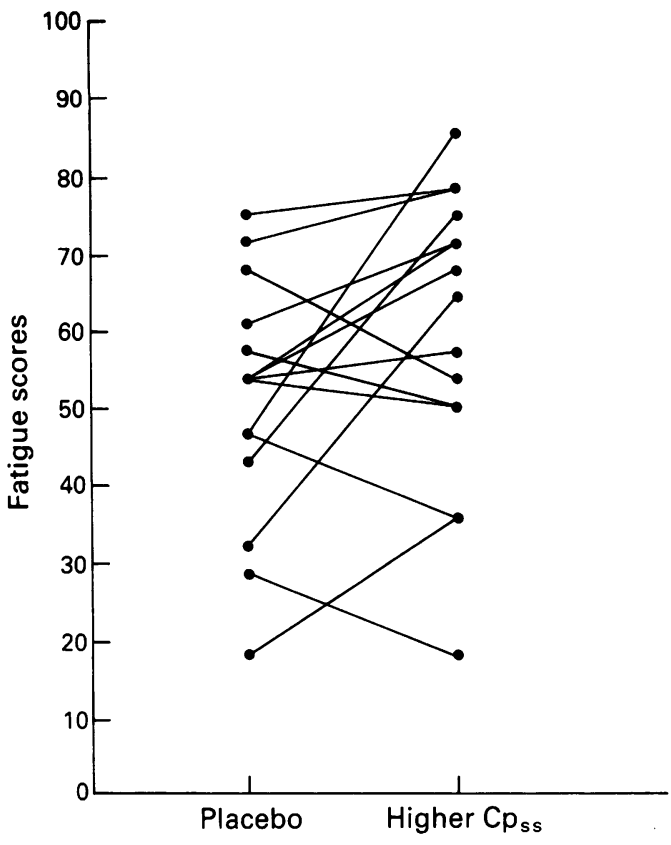

Figure 4 Self rated fatigue scores (100="no symptoms") with placebo and at the higher average steady state plasma concentration $\left(C p_{s s}\right)$ of theophylline.

ent from either of them. Our minimum detectable mean difference proves to be $98 \mathrm{~m}$ or $53 \%$ of the overall mean.

QUALITY OF LIFE QUESTIONNAIRE

Figure 3 shows that theophylline treatment improved subjective dyspnoea in everyday living $(\mathrm{p}<0.005)$, averaging 15 percentage points with the high dose (CI $5 \cdot 7$ to 23 ). Also significant $(p<0.05)$ was the reduction in everyday fatigue with the high dose (fig 4), with a mean change of 9 (CI 2.3 to 14 ) points. Emotional and mastery scores were not significantly different. As above, our minimum detectable mean differences for emotional function and mastery were $15 \%$ and $15 \cdot 5 \%$ respectively.

Weak but conventionally significant correlations were found between reported feelings of breathlessness and fatigue in everyday activities $\left(p<0.05, r^{2}=0.27\right)$ and distance walked on the treadmill test $(p<0.02$, $\left.r^{2}=0 \cdot 304\right)$. There was no correlation between any of the other differences ascribed to treatment and the corresponding changes in any other index.

\section{Discussion}

In this study physical symptoms, exercise capacity, and performance in some pulmonary function tests were improved by theophylline, without any effect on the patient's emotional state. Apart from the stated exclusion criteria we ensured that the subjects were unselected by including all eligible patients, who represent predominantly the lower social classes in generally poor circumstances living in our area of former heavy industry. We are reasonably confident that 
the events and overall findings reported here indicate the likely outcome in treating chronic obstructive lung disease in such a population.

The size of the mean improvement in subjective breathlessness in everyday activities is clearly big enough to be clinically desirable. Other studies of comparable subjects have searched in various ways for signs of change. The results of four of them ${ }^{22-25}$ coincide with our finding of statistically acceptable improvements. In three ${ }^{26-28}$ there were discerned trends that fell short of the conventional $\mathrm{p}<5 \%$ probability criterion. In four ${ }^{29-32}$ no effect was discovered. No study concluded that theophyliine made people feel worse. The variation in these results may be ascribed to the different sensitivities of the methods used and within these limits are consistent with a tendency for improvement with treatment.

Our subjects walked almost half as far again with theophylline as with their usual treatment alone. Nine relevant papers provide comparable data on the relation between theophylline and walking or bicycle exercise. Three ${ }^{24} 3334$ conclude that theophylline is as effective as a $\beta$ adrenergic drug in improving exercise performance. Three more ${ }^{263035}$ give results that are equivocal on this point. Two ${ }^{23} 36$ conclude that there is no effect and one ${ }^{37}$ that theophylline worsens walking ability. Again, difficulties with design or analysis can be identified in each case to support the finding that there is generally a small real benefit.

Previous workers have found no improvement in the spirometric indices greater than about $15 \% .{ }^{33}$ Our results are in agreement.

Chrystyn $e t$ al ${ }^{19}$ have claimed that trapped gas is a more sensitive measure of response to bronchodilators than spirometric indices. Our mean value of 1.5 litres coincides with those of Comroe's ${ }^{18}$ and Chrystyn's groups in emphysema. Our observed reduction with treatment corresponds closely to those of the latter group. We can find no other published evidence. We found this an awkward measurement. It added the difficulties and errors of plethysmography to those of the helium rebreathing technique. Cooperation was often reluctant. We suspect that the width of the variance results in part from subtle errors in performing the tests.

Mood, attitudes, and beliefs affect physical performance ${ }^{38}$ and may well affect the incidence and severity of subjective symptoms. The weak associations we found suggest that people who improve in their self assessed breathlessness in everyday life also improve in their feelings of fatigue and tend to be able to walk further. It is claimed that theophylline makes people feel nervous, restless, and tremulous, with stimulation of the central nervous system. ${ }^{39}$ Guyatt $e t a l^{33}$ found a small improvement in emotional state with theophylline. Our study detected no change. Power analysis applied to this result shows that we can be $70 \%$ confident that we have not missed a change greater than $10.5 \%$. No other report gives comparable data.

Our patients felt a little less fatigued in everyday life with treatment. Apart from ourselves, only Guyatt's group have asked questions about fatigue. They found that there were statistically significant benefits from both salbutamol and theophylline, which were of similar degree, with an additive effect when the two drugs were used together.

If theophylline effects do include more than bronchodilation probably time will be needed for them to emerge. Some of the improvements recorded by our subjects after six weeks' treatment may be attributable to non-bronchodilator effects even though these were not measurable in themselves.

In conclusion, long term theophylline treatment with steady state plasma concentrations maintained at about $17 \mathrm{mg} / 1$ results' in useful improvements in the lives of many patients with clinically important obstructive disease without harmful effects.

We are grateful to Napp Laboratories for supplying all the tablets. We also wish to express our appreciation to Katherine Moir and John Stenhouse for technical assistance and to Gordon Thomson and Lesley Ann Williams for help with prescription arrangements and with checking compliance.

1 Hill N. The use of theophylline in "irreversible" chronic obstructive pulmonary disease. Arch Intern Med 1988;148:2579-84.

2 Addis GJ. Theophylline in the management of airflow obstruction 1. BMF 1990;300:928-9.

3 Johnston IDA. Theophylline in the management of airflow obstruction $2 B M f$ 1990;300:929-31.

4 Wolkove N, Dajczman E, Colacone A, Kreisman H. The relationship between pulmonary function and dyspnoea in obstructive lung disease. Chest 1989;96:1247-51.

5 McGavin C, Gupta S, McHardy GJR. Twelve-minute walking test for assessing disability in chronic bronchitis. BMF 1976;i:822-3.

6 Pineda H, Haas F, Axen K, Haas A. Accuracy of pulmonary function tests in predicting exercise tolerance in chronic obstructive pulmonary disease. Chest 1984;86:564-7.

7 Knox A, Morrison J, Muers M. Reproducibility of walking test results in chronic obstructive airways disease. Thorax 1988;43:388-92.

8 Mahler D, Weinberg D, Wells C, Feinstein A. The measurement of dyspnoea. Chest 1984;85:751-8.

9 Beaumont A, Cockcroft A, Guz A. A self paced treadmill test for breathless patients. Thorax 1985;40:459-64.

10 Guyatt G, Berman L, Townsend M, Pugsley S, Chambers L. A measure of quality of life for clinical trials in chronic lung disease. Thorax 1987;42:773-8.

11 Whiting B, Kelman AW, Barclay J, Addis GJ. Modelling theophylline response on individual patients with chronic bronchitis. Br f Pharmacol 1981;12:481-7.

12 Struthers AD. Theophylline: the modelling and prediction of pharmacological response [MD thesis]. Glasgow: University of Glasgow, 1983 .

13 Shohat B, Volovitz B, Varsano I. Induction of suppressor $T$ cells in asthmatic children by theophylline treatment. Clin Allergy 1983;13:487-93.

14 Torphy TJ, Undem BJ. Phosphodiesterase inhibitors: new opportunities for the treatment of asthma. Thorax 1991;46:512-523.

15 American Thoracic Society. Standards for the diagnosis and care of patients with chronic obstructive pulmonary disease (COPD) and asthma. Am Rev Respir Dis 1987;136:225-44.

16 Kelman AW, Whiting B, Bryson SM. OPT. A package of computer programs for parameter optimisation in clinical pharmacokinetics. $\mathrm{Br} F \mathrm{Clin}$ Pharmacol 1982; 14:247-56.

17 Ullah MI, Cuddihy V, Saunders KB, Addis GJ. How many blows really make an $\mathrm{FEV}_{1.0}$, FVC, or PEFR? Thorax 1983;38:113-8.

18 Bedell GN, Marshall $\mathrm{R}$, Dubois AB, Comroe JH. Plethysmographic determination of the volume of gas trapped in the lungs. $f$ Clin Invest 1956;35:664-70.

19 Chrystyn H, Mulley B, Peake M. Dose response relation to oral theophylline in severe chronic obstructive airways disease. $B M \mathcal{F}$ 1988;297:1506-10.

20 Roberts AJ, Pugh JR, Thomson NC. A new adaptable computerised system for the measurement of specific airways conductance. $\mathrm{Br} \mathcal{F}$ Dis Chest 1986;80:218-28

21 Stark R, Guz A. Assessment of breathlessness. In: Conway J, ed. Dyspnoea. Alderley Edge: Pharmaceuticals Division, ICI, 1984:9-11.

22 Murciano D, Auclair M, Pariente R, Aubier M. A ran- 
domized, controlled trial of theophylline in patients with severe chronic obstructive pulmonary disease. $N$ Engl $f$ Med 1989;320:1521-5.

23 Mahler D, Matthay R, Snyder P, Wells C, Loke J. Sustained-release theophylline reduces dyspnea in nonreversible obstructive airway disease. Am Rev Respir Dis 1985;131:22-5.

24 Guyatt G, Townsend M, Keller J, Singer J, Nogradi S. Measuring functional status in chronic lung disease: conclusions from a randomized control trial. Respir Med 1989;83:293-7.

25 Taylor DR, Buick B, Kinney C, Lowry RC, McDevitt DG. The efficacy of orally administered theophylline inhaled salbutamol and a combination of the two in the management of chronic bronchitis with reversible airflow obstruction. Am Rev Respir Dis 1985;131: 747-51.

26 Eaton M, Macdonald F, Church T, Niewohner D. Effects of theophylline on breathlessness and exercise tolerance in patients with chronic airflow obstruction. Chest 1982;82:538-42.

27 Marvin PM, Baker BJ, Dutt AK, Murphy ML, Bone RC. Physiologic effects of oral bronchodilators during rest and exercise in chronic obstructive pulmonary disease. Chest 1983;84:684-9.

28 Greening A, Baillie E, Gribbin H, Pride N. Sustained release oral aminophylline in patients with airflow obstruction. Thorax 1981;36:303-7.

29 Alexander M, Dull W, Kasik J. Treatment of chronic obstructive pulmonary disease with orally administered theophylline. $\mathcal{F} A M A$ 1980;244:2286-90.

30 Dullinger D, Kronenberg R, Niewohner DE. Efficacy of inhaled metaproterenol and orally-administered theophylline in patients with chronic airflow obstruction.
Chest 1986;89:171-3.

31 Clark CJ, Boyd G. Combination of aminophylline and salbutamol in the management of chronic obstructive airways disease. Br f Clin Pharmacol 1980;9:359-64.

32 Jenkins PF, White JP, Jariwalla AJ, Anderson G, Campbell IA. A controlled study of slow-release theophylline and aminophylline in patients with chronic bronchitis. $\operatorname{Br} \mathcal{F}$ Dis Chest 1982;76:57-60.

33 Guyatt GH, Townsend M, Pugsley SO, Keller JL, Short HD, Taylor DW, et al. Bronchodilators in chronic airflow limitation. Am Rev Respir Dis 1987;135:1069-74.

34 Leitch AG, Morgan A, Ellis DA, Ball G, Haslett C, McHardy GJR. Effect of oral salbutamol and slowrelease theophylline on exercise tolerance in chronic bronchitis. Thorax 1981;36:787-9.

35 Vereen L, Kinasewitz G, George R. Effect of aminophylline on exercise performance in patients with irreversible airway obstruction. Arch Intern Med 1986; versible airway

36 Kongragunta VR, Druz WS, Sharp JT. Dyspnoea and diaphragmatic fatigue in patients with chronic obstructive pulmonary disease. Am Rev Respir Dis 1988;137: 662-7.

37 Evans WV. Plasma theophylline concentrations, six minute walking distances, and breathlessness in patients with chronic airflow obstruction. BMF 1984;289: 1649-51.

38 Morgan A, Peck D, Buchanan D, McHardy GIR. Effect of attitudes and beliefs on exercise tolerance in chronic bronchitis. BMF 1983;286:171-3.

39 Rall TW. The methylxanthines. In: Gilman AG, Goodman LS, Rall TW, Murad F, eds. Goodman and Gilman's The pharmacological basis of therapeutics. 7th ed. New York: Macmillan, 1985: 589-63. 